\title{
artículos
}

\section{Pablo Picasso y la cinematografía}

\author{
Laura Franco Carrión
}

Investigadora vinculada a la UMA

\section{RESUMEN}

Son diversos y amplios los campos en los que Pablo Picasso desarrolló su actividad artística. Conocidas son sus intervenciones en ámbitos diversos, incluidos la fotografía y el cine.

En este caso, queremos dirigir la mirada hacia un campo aun no demasiado conocido en el que Pablo Picasso se desenvolvió y a través del cual pudo recibir influencias importantes para su propia producción artística. Nos estamos refiriendo a la relación entre Picasso y la cinematografía.

PALABRAS CLAVE: Pablo Picasso/ cinematografía/ película/ cubismo/ Le mystère Picasso/ La mort de Charlotte Corday/ Guernica.

\section{Pablo Picasso and cinematography}

\section{ABSTRACT}

Diverse and broad are the fields in which Pablo Picasso developed his artistic activities. His interventions in many different disciplines including photography and film are not a mistery for anyone.

In this work, we want to focus on a field that is not very well-known yet, where Pablo Picasso developed himself and which may have served him as an imput of important influences to his own artistic production. We are talking about the relationship between Picasso and cinematography.

KEY WORDS: Pablo Picasso/ Cinematography/ film/ cubism/ Le mystère Picasso/ La mort de Charlotte Corday/ Guernica.

1. Colaboraciones, co-autorías, autorías y participaciones diversas entorno AL CINE.

Pablo Picasso, bien pudiera haber presumido de ser el pintor al que se le han dedicado más recursos audiovisuales y de las formas más dispares posibles.

Creyendo conveniente adentrarnos no sólo en aquellos factores cinematográficos de principios del siglo $X X$ que influyeron en el surgimiento y desarrollo del Cubismo de Pablo Picasso, a lo largo de este artículo, comprobaremos lo fértil y fructífera que fue la relación entre Picasso y el cine, viendo al artista en ocasiones como colaborador, autor o co-autor (actor esporádico o como mera influencia) en la creación de un material audiovisual heterogéneo .

*FRANCO CARRIÓN, Laura: "Pablo Picasso y la cinematografía", en Boletín de Arte n 32-33, Departamento de Historia del Arte, Universidad de Málaga, 2011-2012, págs. 265-280. Fecha de recepción: Enero de 2011. 
Para la elaboración de este documento, hemos tenido especialmente en cuenta dos monografías esenciales entorno a "Picasso y el cine". La primera titulada Picasso en el cine también, de Fernández Cuenca así como Picasso à l'écran, en la cual tenemos acceso al estudio de Marie-Laure Bernadac «Picasso et même le cinéma».

Por último y como síntesis de las monografías mencionadas, hemos de destacar la conferencia titulada "Picasso y el cine", llevada a cabo por Agustín Sánchez Vidal y publicada por la Fundación Cultural Mapfre Vida, la cual ha resultado de gran utilidad por su completa síntesis, para el desarrollo de este trabajo.

\section{- La llegada tardía de Picasso al cine.}

Tal y como es nuestro objetivo demostrar en este trabajo, Picasso se vio influenciado por el cine desde aquellas primeras proyecciones a las que asistió siendo aun muy joven, en la primera y segunda década del siglo XX.

Sin embargo, no es hasta la década de los cincuenta cuando se involucra de forma activa en la creación cinematográfica dando lugar a una filmografía que podríamos denominar genuinamente picassiana.

Es significativo cómo, durante la década de los años treinta, Picasso aparece en dos películas casualmente españolas. Una de ellas Esencia de verbena «poema documental de Madrid en 12 imágenes», realizada por Ernesto Giménez Caballero, donde aparecen determinados grabados del artista.

Posteriormente en 1937, otra obra cinematográfica vuelve a ocuparse de Picasso y su Guernica en El Pabellón de España en la Exposición Internacional de París, documental rodado durante la Guerra Civil por la productora del Partido Comunista Español, Film Popular ${ }^{1}$.

Durante la posguerra se asentó un nuevo género fílmico. Nos referimos a las "películas sobre arte", surgidas en Europa como variante del documental. Este tipo de películas, se encargaban de resaltar la barbarie de la guerra, al mismo tiempo que aportaba ciertas dosis de esperanza, al mostrar un patrimonio cultural dentro de un continente devastado por el conflicto bélico. Este patrimonio cultural al que aludían los filmes, se situaban como iconos aun vigentes, augurando tiempos mejores aún por venir.

Como cita también Sánchez Vidal, no es de extrañar que la figura de Picasso resultase atractiva para cineastas pioneros en el cine sobre arte como Paul Haesaerts,

1 1937. EL PABELLÓN DE ESPAÑA EN LA EXPOSICIÓN INTERNACIONAL DE PARÍS.

Producción Film Popular. Barcelona. España.

Blanco y negro. 20 minutos. 
Alain Resnais o Luciano Emmer, que veían en la figura del pintor malagueño un mecanismo para apaciguar el conflicto ${ }^{2}$.

Quizá, por este motivo que señalamos, la década de los cincuenta fue aquella que vio a Picasso implicarse más activamente en el medio cinematográfico, a través de la participación en rodajes, que lo sitúan como protagonista o como director.

En estos diez años, es preciso destacar que se comienzan a llevar a cabo de forma más asequibles las películas en color, aspecto esencial para la filmación de pinturas.

Como compartimos con Fernández Cuenca y Sánchez Vidal, esta década de los cincuenta que podríamos calificar de floreciente relación entre Picasso y el cine, comienza en 1949 con la película de Nicole Vérdrès La vie commence demain. Después continúa con el Guernica (1949-1950) de Alain Resnais y Robert Hessens y Visite à Picasso de Paul Haesaerts, de 1950, obras mencionadas en el siguiente apartado en el que tratamos principalmente la figura de Picasso como fuente de inspiración para la creación cinematográfica .

Durante 1950, el pintor rueda La mort de Charlotte Corday e inicia su colaboración con Robert Picault a través de cuatro cortometrajes que aluden a su creación entorno a la cerámica durante su estancia en Vallauris, que seguirá durante 1951 con Robert Mariaud.

En 1953 encontramos la obra cinematográfica Picasso de Luciano Emmer y en 1955 Le mystère Picasso, realizado por Clouzot.

Posteriormente Picasso aparecerá como actor ocasional en diversas obras, entre ellas Le testament d'Orphée de Jean Cocteau (1959), como espectador de una corrida de toros ${ }^{3}$.

Como paradigmas de la relación creativa entre Picasso y el cine, situando al artista, como parte activa en la creación de determinadas obras cinematográficas, consideramos centrarnos en dos obras concretamente; La mort de Charlotte Corday y Le mystère Picasso.

\section{- La mort de Charlotte Corday.}

Esta película a la que nos referimos como obra también perteneciente a Pablo Picasso, no llegó a ser montada ni explotada comercialmente, aunque sí exhibida en

2 SÁNCHEZ VIDAL, Agustín: "Picasso y el cine". Picasso.Fundación cultural Mapfre Vida, D.L. ,Madrid, 2002,pp. 321.

3 FERNÁNDEZ CUENCA, Carlos : Picasso en el cine también. Editorial Nacional, Madird, 1971. 
el Festival de Antibes. Este hecho junto a otros testimonios y documentos permiten dar cuenta de su relevancia.

La producción del proyecto corrió a cargo del director de la Cinemateca Francesa, Henri Langlois. Este mismo, en la edición anterior del Festival de Antibes, propuso a Picasso la realización de "películas de artistas", que incluiría también a Matisse, Braque, Cocteau, Cendras y Queneau, entre otros.

Se trataba de una idea que pretendía poner todos los medios cinematográficos posibles al alcance de artistas no necesariamente vinculados con este medio para que se expresaran libremente a través del mismo.

Picasso se situaría como el primer artista, con la asistencia técnica de Frédéric Rossif, la ayuda de un operador y cinta virgen proporcionada por Iris Barry, de la Filmoteca del MOMA. La duración debía mantenerse en una hora aproximadamente y se quería estrenar en la Cinemateca Francesa en diciembre de $1950^{4}$.

A lo largo de un mes aproximadamente, Picasso se dedicó por entero a dirigir el filme, mediante improvisaciones a partir de un esquema provisional.

Efectuaba apariciones delante de la cámara ensamblando materiales encontrados (cartón ondulado, alambre, cerámicas, maderas, desechos...), pintaba sobre los cuerpos de las personas que se encontraban alrededor, componía pequeñas escenografías de terracota, entre muchas y diversas ideas que fueron surgiendo de forma espontánea durante el rodaje .

Picasso ya había abordado la temática relativa a "La muerte de Marat", en algunas de sus pinturas y grabados entre 1931 y 1934.

Cabe mencionar con respecto a la relación entre Picasso y la obra "La muerte de Marat",el trabajo llevado a cabo por Inocente Soto Calzado ${ }^{5}$, que dedica su tesis doctoral a investigar en esta dirección.

En el caso de esta película, el título alude de forma simétrica al título de la obra de Jacques-Louis David.

Laprotagonista, Charlotte Corday, asesina de Marat, es evocadaenellargometraje, a través de una máscara de cartón ondulado y pintado, cuyo cuerpo se muestra cubierto con tela de flores. Aparece tendida sujetando e una de sus manos un trozo de madera.

4 SÁNCHEZ VIDAL, Agustín, op.cit; p.324.

5 SOTO CALZADO, Inocente: La creacion según Picasso : la muerte de Marat. Granada : Universidad, Facultad de Bellas Artes, Departamento de Pintura, 2003. 

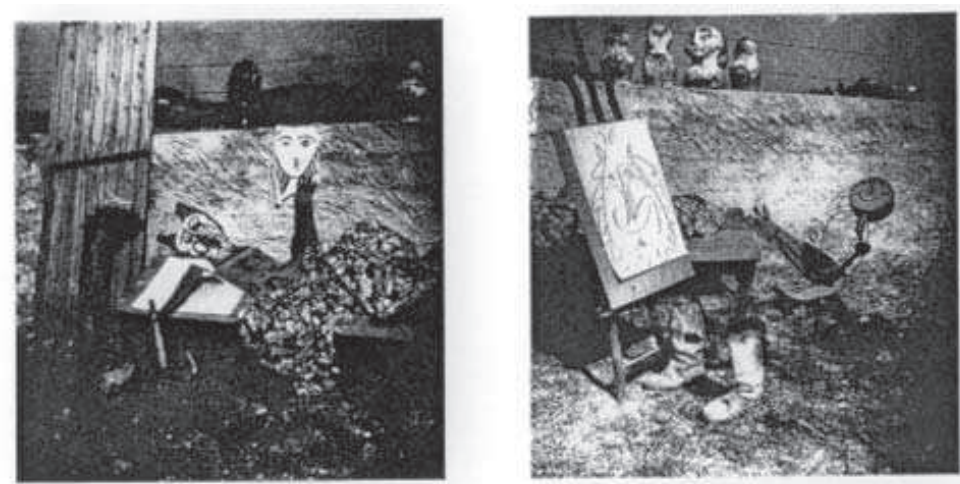

1. A la derecha aparece la evocada "Charlotte Corday" por Picasso y Frédéric Rossif. A la izquierda otra imagen de La mort de Charlotte Corday de 1950, "El pintor y su modelo".

Puede observarse la reconstrucción de un segundo personaje que "recuerda a Don Quijote, reconstruido plásticamente mediante una coraza y sosteniendo en sus manos una paloma de papel”,(Sánchez Vidal, 2002).

Un tercer personaje, es creado para representar un tema muy vinculado a Picasso, el del pintor y su modelo. Para la construcción de este tercer personaje utiliza materiales como unas botas viejas, cartón o alambre.

Junto a los "personajes ficticios", se encontraban los propios Picasso y Rossif, que aparecían en escena con máscaras y haciendo de monstruos.

En cuanto a los demás personajes de "carne y hueso", el artista iba fabricándolos a medida que los necesitaba, efectuando pintadas sobre los rostros, torsos, extremidades u otras partes del cuerpo. [1]

Más adelante, sobre una mesa Picasso, dispuso un grupo de figurillas de terracota de entre quince y veinte centímetros de altura aproximadamente, con la ayuda de Robert Picault.

Una muestra descriptiva del escenario creado, se compuso por una ciudad antigua, con templos y columnatas. Dentro de esta ciudad Picasso introdujo su característico bestiario de faunos, sátiros y ninfas.

El fondo se cerraba a través de láminas de cobre y el conjunto se iluminaba mediante reflexión, con chapas de metal. 
El interior estaba formado al estilo de las casas de muñecas, en miniatura y dotando la escena de un carácter burgués.

Tanto esta película como Guernica, de la cual nos ocuparemos en el siguiente apartado, a pesar de distar mucho en cuanto a la temática y el tono, coinciden en un aspecto significativo y es que ambas adoptan materiales plásticos para reorganizarlo al servicio de un desarrollo fílmico argumental.

\section{- Le mystère Picasso ${ }^{6}$.}

A pesar de que el criterio que hemos seguido en este trabajo, sitúa como objeto de análisis en primer lugar Le mystère Picasso a otras obras como Visite à Picasso de Paul Haesaerts o Picasso de Luciano Emmer, hemos de reseñar que Le mystère Picasso, se benefició altamente de las aportaciones anteriores introducidas en estas obras cinematográficas citadas, así como de la experiencia con la que ya contaba Picasso delante y detrás de las cámaras.

A estos antecedentes y hallazgos previos, debemos sumar la experiencia del director Henri-Georges Clouzot, que no procedía del documentalismo artístico sino del cine comercial y policíaco.

La propia película, en su comienzo y a través de una voz en off del realizador, nos adelanta la información con la que nos vamos a encontrar a continuación.

Sánchez Vidal, hace referencia a esta voz en off como un agente encargado de atraer al público con expresiones más propias de "espectáculos circenses" como "estar en la cuerda floja" o "el drama del genio".

Así mismo, califica la intervención de Picasso en el filme como la manera en que el pintor se plantea muy explícitamente la ejecución de ciertos motivos como si fueran auténticas faenas toreras, con su dramatismo, sus tanteos, sus revolcones y su entrar a matar, logrando salir airoso de embestidas que para otros podrían haber sido mortales.

La relación entre Picasso y Clouzot era larga y duradera, estando vinculados por una amistad de veinte años.

Picasso y Clouzot se reencontraron en Nimes en una corrida de toros y es durante ese encuentro donde surgió la idea de una colaboración cinematográfica entre ambos. [2]

\footnotetext{
6 1954. EL MISTERIO PICASSO (LE MYSTERE PICASSO).

Producción : Filmsonor. Francia.

Productores : Henri-Georges Clouzot y Pablo Picasso. Productor asociado : Georges Loureau. Director: HenriGeorges Clouzot. Secretaria de rodaje : Jaqueline Roque. Fotografía : Claude Renoir. Segundo operador: Jacques Métehen. Sonido : Joseph de Bretagne. Montaje: Henri Colpi. Blanco y negro y Eastmancolor. Pantalla normal y cinemascopio. 82 minutos.Estreno en Madrid : Cinema Palace, 25 de marzo de 1968.
} 


\section{Picasso y Henri-Georges} Clouzot durante el rodaje de Le mystère Picasso.

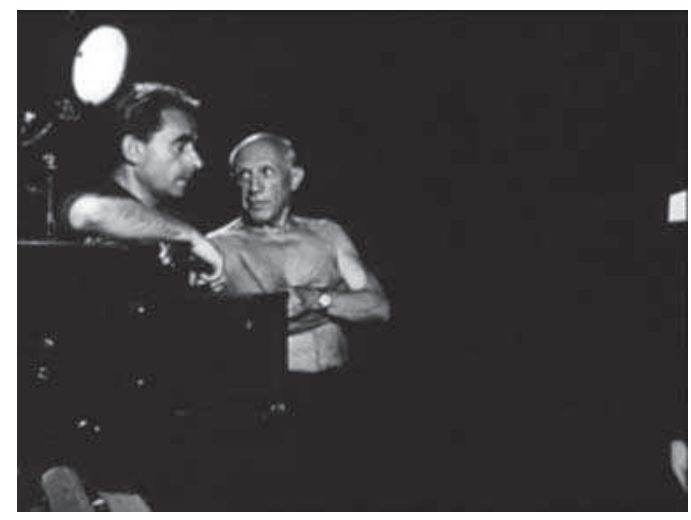

Tras ese encuentro, Picasso recibió procedente de Estados Unidos unos dispensadores de tinta que traspasaba el papel y que, como se observa en la película, eran un prototipo de rotulador.

Para la filmación, encargaron un papel especial, consiguiendo así dibujar por una de las caras del papel y que este dibujo se trasparentara por el otro lado, donde estaba situada la cámara7.

Con esta acción Clouzot consiguió aunar tanto las experiencias recogidas en Visite à Picasso como en Jackson Pollock de 1951 y perteneciente a Hans Namuth y Paul Falkenberg a través de la imposición de vidrios transparentes sobre los cuales se pintaba ${ }^{8}$.

El director de fotografía de la película fue Claude Renoir, nieto del pintor impresionista Auguste Renoir y la música creada por Georges Auric, encargado de entablar una relación entre su música y el ámbito cinematográfico de la mano de Jean Cocteau años atrás, encargándose de las partituras de todas sus películas además de componer para otros directores, entre ellos el propio Clouzot ${ }^{9}$.

El montaje de la película pertenece a Henri Colpi quien publicó un artículo en Cahiers du Cinéma ${ }^{10}$ en el que explica la técnica de Le mystère Picasso.

Ciertamente, en esta película el montaje es muy importante ya que se pueden observar fragmentos en los que tal y como se cita en las fuentes a las que hemos recurrido "el objetivo de la cámara fija hasta cien momentos distintos de una pintura

7 FERNÁNDEZ CUENCA, Carlos, op.cit; p.151- 175.

8 FERNÁNDEZ CUENCA, Carlos, ibidem.

9 FERNÁNDEZ CUENCA, Carlos, ibidem.

10 COLPI, Henri. Comment est né 'Le mystère Picasso'. Cahiers du Cinéma, № 58, pp. 2 - 9. Abril, 1956. 


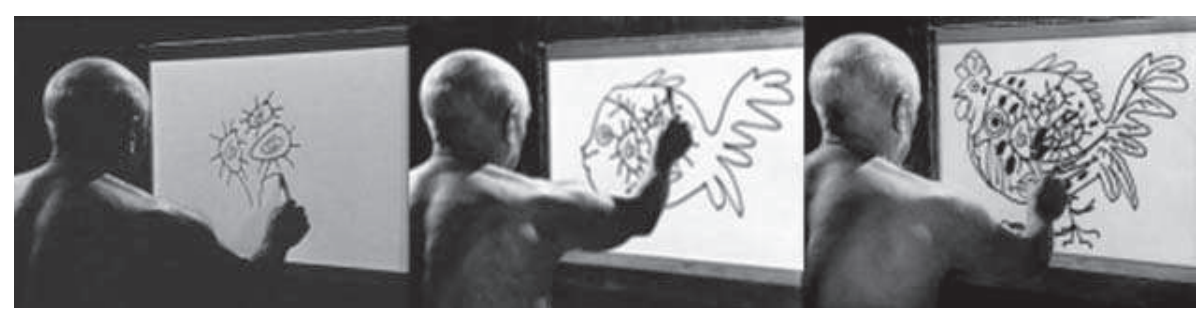

3. Secuencia en la que Clouzot pregunta a Picasso si se cree capaz de pintar algo en cinco minutos que quedan de película.

Picasso pinta lo que primero parecen flores, luego pasa a ser un pez, continúa siendo un ave y acaba transformado en fauno.

que se filma con un mismo encuadre"11.

Este factor da lugar a ejercer una gran precisión en los empalmes, lo cual evitó la percepción indebida de saltos, que habrían molestado durante el seguimiento en la actividad de Picasso durante la filmación que sin duda es rigurosa, y segura.

El rodaje de la película resultó ser agotador. Estuvieron grabando durante julio, agosto y septiembre de 1955, llegando a rodar hasta catorce horas seguidas. En ocasiones, Picasso tenía que levantarse, desplazarse y volverse a sentar más de cien veces en una hora, además de soportar el calor de los focos y del propio mes de agosto. Todos estos factores se unían a la tensión que suponía no solo estar pintando, sino hacerlo frente a las cámaras.

Lo que en principio iban a ser unos veinte minutos de película, se convirtió en el doble debido al constante ritmo de trabajo de Picasso y a la seguridad con la que trabajaba.

Finalmente la película y no cortometraje, fue estructurada en dos partes. La primera de ellas, que abarca los primeros cincuenta minutos, el pintor utiliza el sistema que describimos anteriormente con los roturadores y el papel traslúcido. [3]

Gracias a la técnica descubierta, podemos acceder a la manera y el ritmo de trabajo del artista.

Los trazos van apareciendo de manera casi "mágica", ya que la disposición de los focos, nos ofrecen la ilusión de transmitir el avance de un dibujo que se va creando solo, al no poder ver al pintor tras el papel.

En la segunda parte de la película, Picasso comienza a utilizar óleo, por lo que

11 SÁNCHEZ VIDAL, Agustín, op.cit; p. 332. 
el sistema de transparencias queda ya descartado, siendo la cámara ahora la que se pone de lado del pintor para filmar trazo por trazo, teniendo el artista que levantarse después de cada pincelada.

En este caso, siendo imposible la filmación en directo, la cámara condensa en unos pocos minutos, horas y días de trabajo.

Pueden observarse aspectos significativos como los cambios de color cuando la pincelada se ha secado o determinados retoques, lo que resta espontaneidad, como en el caso de las obras llevadas a cabo durante la primera parte de la película pero añade modificación y por consiguiente exploración y transformación de la obra, algo que como el propio Picasso apuntó, constituye la esencia de su modo de estar ante el cuadro.

La parte final de la película, se centra en la obra los Bañistas en la playa de la Garoupe, que es captada por el Cinemascope y su formato panorámico.

Gracias a dicho formato, tenemos la oportunidad de acceder a cada uno de los pasos que ofrece la evolución de esta obra, en la que cada etapa constituye una obra en sí misma siendo el punto de partida muy distinto del resultado final o de la multitud de escenas intermedias.

Como ejemplo ilustrativo traslado para cerrar este epígrafe, un comentario que Carlos Fernández Cuenca incluye en su libro Picasso en el cine también acerca de lo que supone para él, esta película :

"Después de haber visto varias veces El misterio Picasso -en el ambiente excepcional del Festival de Cannes, y en una sala comercial de París, y rodeado de pintores y críticos de arte en sesión privada madrileña, y con un público de aficionados al documental en Bilbao- y tras de descifrar y ordenar las notas tomadas a oscuras y de meditar sobre ellas, resulta evidentísimo para mí que en esta deslumbradora improvisación de creación ritmada y completa, que va de menor a mayor, con las alternativas que corresponden a la acción visual.

Es posible, pues no he podido averiguar su exacta cronología, que el orden de composición de las obras no sea el mismo con que aparecen en la pantalla, pero el dato importa poco para la conclusión admirativa. Por genialidad de Picasso o por sabiduría de Clouzot, la construcción dramática responde a certero rigor de temas y atributos"12.

12 FERNÁNDEZ CUENCA, Carlos, , op. cit; p.170. 


\section{Aportaciones de Pablo Picasso al arte cinematográfico.}

Como hemos podido comprobar en el apartado 4.1, Picasso vio en el cine, un mecanismo más para expresarse y experimentar, dando rienda suelta a su necesidad creadora, siendo esta necesidad a la que aludimos, la participe de que el artista se introdujera de igual forma en otras artes como la literatura, la escultura o la escenografía.

Al mismo tiempo, fueron varios los cineastas que encontraron en Picasso una fuente de recursos para sus creaciones cinematográficas, bebiendo de la propia creación artística del pintor para elaborar y construir sus mensajes audiovisuales con un estilo propio.

En este sentido, el material disponible también es heterogéneo, hallando obras como Guernica de Alain Resnais y Robert Hesens, autores de reconocido prestigio. Esta obra además se encuentra complementada por textos de Paul Eluard.

Por otra parte, encontramos documentales dedicados a la figura del artista, como Picasso ${ }^{13}$, de Luciano Emmer.

En la categoría de ficción, existen algunas películas enmarcadas dentro de la categoría de bio-pic comercial, que reflejan de manera más reconocible o fidedigna, algunos aspectos de la vida del pintor como es el caso de Sobrevivir a Picasso de James Ivory.

Esta película está basada en el libro "Vida con Picasso" de Françoise Gilot y Carlton Lake.

Sin embargo, otros filmes como Picassos Aventyr de Tage Danielsson, nos ofrecen una historia inverosímil y casi por completo ficticia, presentada como un relato disparatado y alocado.

El material que diversos creadores audiovisuales han dedicado a Picasso es tan heterogéneo, que podemos encontrar incluso tres películas de animación (una polaca, una checa y una inglesa), las cuales se centran en obras pictóricas concretas del pintor como Los tres músicos, en las que se da vida a los personajes del cuadro ${ }^{14}$.

13 1953. PICASSO

Producción: Rizzoli Film. Italia

Productor: Sergio Amidei. Guión, dirección y comentario: Luciano Emmer

Fotografía: Giulio Giannini. Música : Roman Vlad. Dirección musical: Franco Ferrara. Solos de guitarra Gangi.

Montaje : Yolanda Benvenuti.

Ferraniacolor. 55 minutos.

14 SÁNCHEZ VIDAL, Agustín, op. cit; p.319. 
Dentro de este material audiovisual tan diverso en cuanto a enfoques, visiones y formatos, también pueden encontrarse programas de televisión dedicados al cubismo, filmaciones de visitas al taller de Picasso, entrevistas a los allegados como en el caso de la obra Picasso Insólito ${ }^{15}$ de Antonio Mercero, e incluso conferencias sobre el artista impartidas por personalidades relevantes dentro del mundo del arte.

Así como en el apartado 4.1, hemos analizado la figura de Picasso como "colaborador activo" en la elaboración de diversas películas, en este apartado que sigue, es nuestra intención mostrar principalmente aquellas obras creadas por otros autores que adoptaron la figura y las obras de Picasso como fuente directa de inspiración.

En esta línea, consideramos oportuno detenernos en dos obras concretamente; $L a$ vie commence demain de Nicole Védrès y el Guernica de Alain Resnais y Robert Hessens.

- La Vie commence demain de Nicole Védrès ${ }^{16}$.

A través de esta típica película de "rearme moral", militante y pedagógico, se trata de aportar nuevas esperanzas de futuro desde una perspectiva progresista mediante la muestra de la actualidad literaria, artística y científica de Francia durante la posguerra.

En este sentido, se introducen los testimonios de personalidades intelectuales como Jeau Paul Sartre, Le Corbusier, André Gide, Jacques Prévert o el mismo Picasso.

Picasso, aparece en diversos ambientes y con distintos acompañantes, como en la playa con François Gillot, el Museo de Antibes junto a Gide o en su taller de Vallauris bromeando junto a diversas piezas de cerámica con Prévert.

Como reza a modo de curiosidad en algunas publicaciones ya mencionadas que tratan la relación entre Picasso y el cine, en esta obra no queda recogida la voz de Picasso aunque Nicole Védrès intentara grabarla después del rodaje para incluirla a la banda sonora. Queriendo compensar dicha carencia, la realizadora añadió a la banda sonora de Darius Milhaud, un poema titulado Lanterna magique de Picasso de Jacques Prévert ${ }^{17}$. [4]

15 1981. PICASSO INSÓLITO

Dirección : Antonio Mercero.

Málaga:Banco de Bilbao.

16 1949. LA VIE COMMENCE DEMAIN.

Dirección : Nicole Védrès.

Blanco y negro, 20 minutos.

17 PRÉVERT, Jacques, «Lanterna magique de Picasso», en Paroles, Gallimard, Le livre de poche, 1964,

París, p. 240. 


\begin{tabular}{|c|c|}
\hline 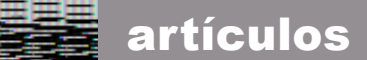 & Laura Franco Carrión \\
\hline
\end{tabular}

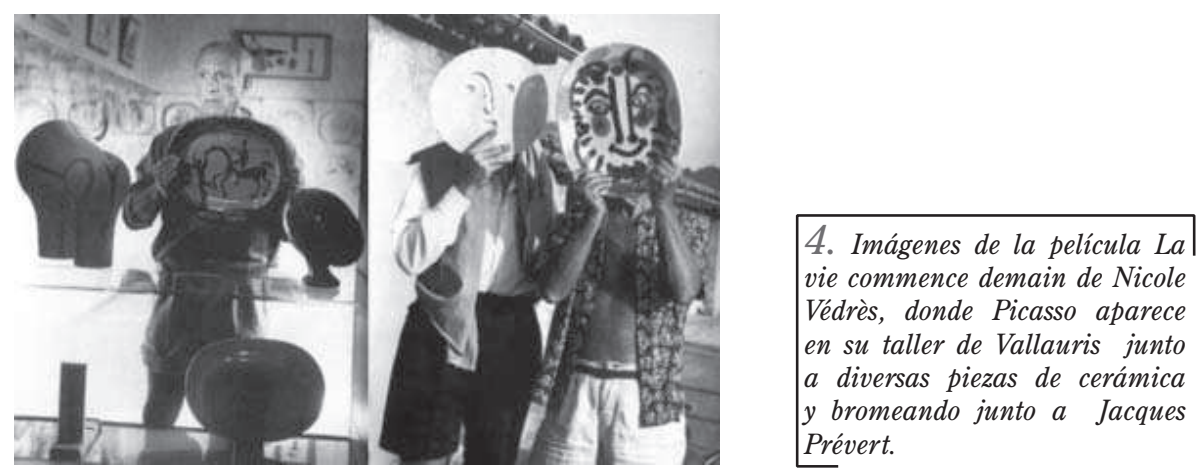

- Guernica de Alain Resnais y Robert Hessens ${ }^{18}$.

Guernica de Alain Resnais y Robert Hessens es un cortometraje caracterizado por determinados aspectos que lo dotan de gran interés a pesar de su corta duración.

En esta obra, el Guernica de Picasso no solo actúa como un icono que sirve para representarse a sí mismo y por consiguiente a la Guerra Civil española, sino que sirve además como medio para poner de manifiesto aspectos clave en la historia mundial como la ascensión del nazismo, la Segunda Guerra Mundial y la bomba de Hiroshima.

Debemos destacar en esta obra una utilización muy trabajada de los recursos fílmicos introducidos. El Guernica, no aparece de forma íntegra sino fragmentado y alternado con otras obras de Picasso, dibujos, grabados, collages, esculturas y cerámicas.

Robert Hessens fue el encargado de elaborar un guión muy cuidado que contó con la revisión de Pablo Picasso. El material filmado se organiza en tres tiempos básicos, tal y como señala Sánchez Vidal: víctimas, verdugos y masacre. Tanto al principio como al final se sitúan un prólogo breve y un cierre con toques esperanzadores ${ }^{19}$.

Al comienzo del cortometraje, podemos observar una imagen de la villa de Guernica en ruinas y posteriormente, obras picassianas pertenecientes a los períodos "rosa" y "azul"en las que podemos ver arlequines y saltimbanquis ordenados a través de una sucesión suave.

Después, el ritmo de la obra cambia a partir de la aparición de un muro cubierto

181949 - 1950. GUERNICA.

Directores : Alain Resnais y Robert Hessens.

Blanco y negro, 15 minutos.

19 SÁNCHEZ VIDAL, Agustín, op. cit; p.323. 


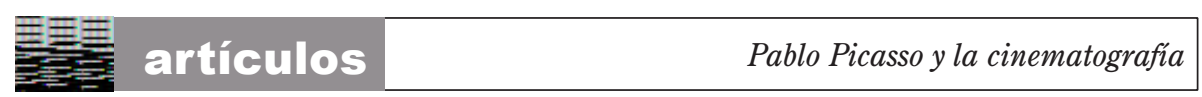

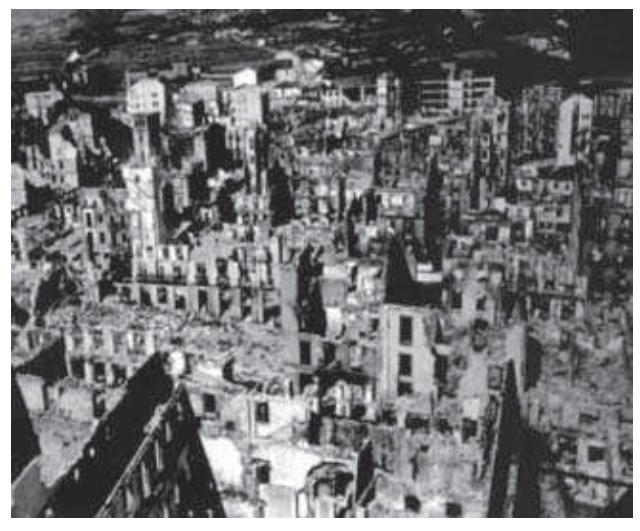

5. Imagen de la ciudad de Guernica tras el bombardeo nazi en Abril de 1937,perteneciente a la película Guernica de Alain Resnais y Robert Hessens.

6. Fragmento del Guernica de Picasso, utilizado por Alain Resnais y Robert Hessens para el cortometraje Gernica.

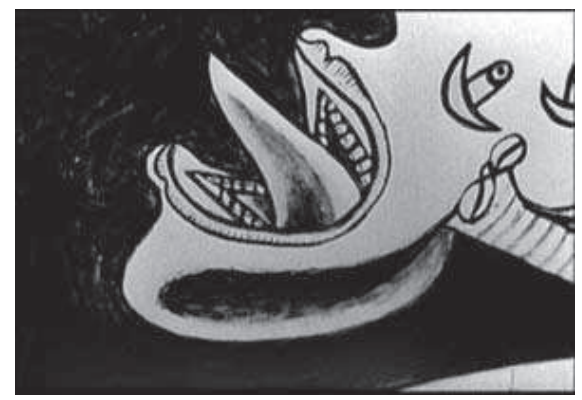

por graffitis. Podemos distinguir el ruido de las ametralladoras y las sirenas, a la par que comienzan a aparecer cuerpos descoyuntados.

A través de un montaje que combina planos muy cortos y movimientos de cámara calificados por Sánchez Vidal como "espasmódicos", nos vamos introduciendo en el Guernica de Picasso.

El ritmo vuelve a tornarse lento mediante un travelling que va escrutando el horror de la masacre que se extiende delante. [5 y 6]

Este cortometraje, parece terminar con un canto a la esperanza mostrando la escultura del hombre con el cordero.

"Esta narrativización y dramatización de los materiales picassianos, valiéndose de recursos de la mejor ley-cinematográficamente hablando-, constituye un hito en la filmografía sobre el pintor, cuyas consecuencias se dejan notar en varias de las películas posteriores, empezando por La mort de Charlotte Corday, que en 1950 dirige el propio pintor", (Agustín Sánchez Vidal, 2002). 


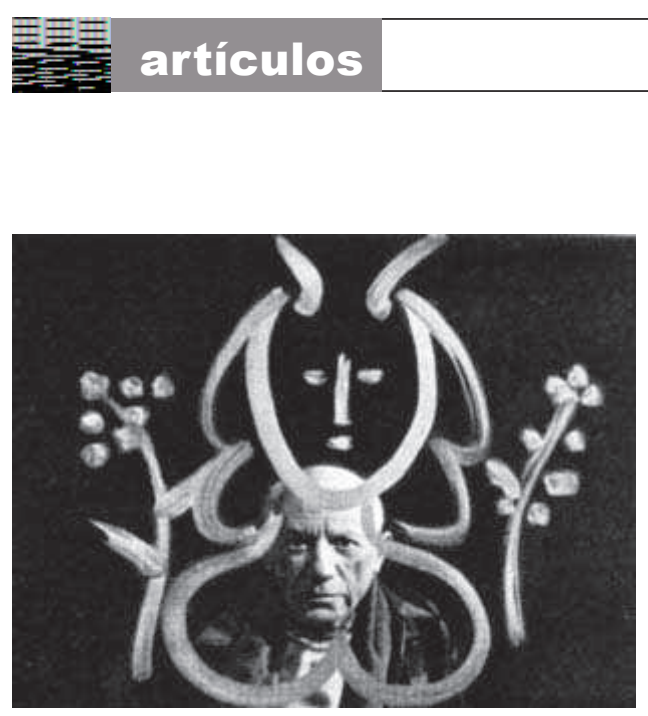

7. Imagen de la película Visite à Picasso de Paul Haesaerts.

La citada obra cinematográfica, perteneciente a Alain Resnais y Robert Hessens, no fue la única que se centró en la obra "Guernica" de Picasso. Con anterioridad, cabe destacar la aparición de determinados testimonios, tanto por escrito como en soporte audiovisual, que centran su interés en la obra mencionada del pintor y la dotan de un carácter vinculado al cine.

En primer lugar debemos mencionar un análisis del "Guernica" como tema cinematográfico que aparece a principios de 1941 en la publicación norteamericana Pacific Art Review, de la mano de Sidney y Harriet Janis y titulado "Picasso`s Guernica : a film analysis"20.

Posteriormente y además del Guernica de Alain Resnais y Robert Hessens, encontramos otras dos obras que se centran en el cuadro de Picasso; la versión de Robert J. Flaherty y la del danés Helge Ernst.

- Otras obras cinematográficas que miran hacia Picasso.

Dentro de esta categoría que hemos fijado de obras cinematográficas que se nutren de Picasso y su actividad artística, podemos encontrar también Visite à Picasso ${ }^{21}$ de 1950, perteneciente al crítico, pintor y cineasta belga Paul Haesaerts . [7]

Rodada en el taller de Vallauris, en esta película podemos ver al artista malagueño dibujar, pintar o esculpir. La cámara muestra especial interés por la obra picassiana La cabra.

Esta película es digna de mención porque utiliza por vez primera un recurso que posteriormente adoptaría Clouzot en su obra Le mystère Picasso : la utilización de un cristal transparente superpuesto entre el pintor y la cámara cinematográfica, en el que Picasso llevaría a cabo diversas pinturas.

La interposición de este cristal entre el artista y la cámara, permitó acceder a

20 FERNÁNDEZ CUENCA, Carlos, op. cit; p. 84.

21 1950. VISITE À PICASSO.

Director: Paul Haesaerts.

Blanco y negro, 21 minutos. 
8. Picasso en su tallerde Vallauris. Imagen perteneciente a la película Picasso de Luciano Emmer.

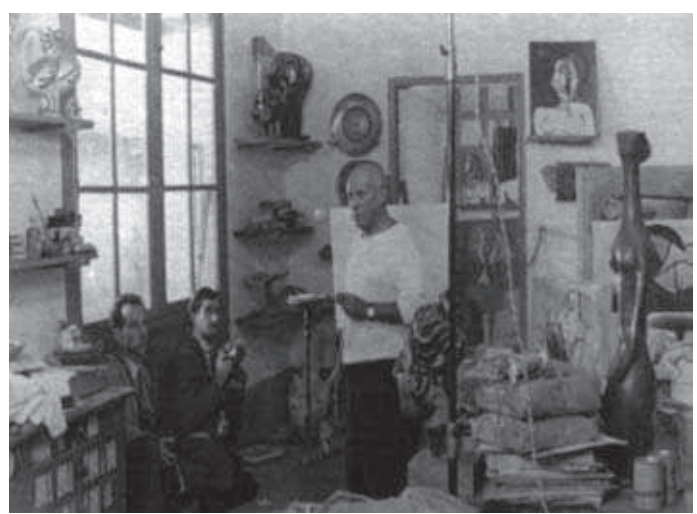

aspectos como la mirada, gestos y reacciones del pintor, así como el curso que seguía su brazo y el pincel en cada trazo, la aplicación de las acentuaciones formales, en qué elemento ponía mayor o menor énfasis. La transparencia de este nuevo lienzo permitió acceder a la manera física, los movimientos corporales y la actitud tomada por Picasso cuando se enfrascaba en sus procesos creadores.

Según explicó Haesaerts, fue complicado trabajar con Picasso ya que se negaba a repetir gestos o a interpretar como un actor profesional con el objetivo de guardar los raccords de continuidad en los cambios de emplazamiento de la cámara.

De Luciano Emmer de procedencia italiana y con una trayectoria cinematográfica centrada en los documentales artísticos significativa, encontramos en 1953 su Picasso ${ }^{22}$.

Emmer se centró en el material procedente de la gran exposición picassiana acontecida en Roma en 1953. Posteriormente capta al pintor malagueño trabajando a su propio ritmo, en su taller de cerámicas de Vallauris y en la Capilla de la Paz de la misma localidad en la cual vemos su gran trabajo de cincuenta metros cuadrados. [8]

Esta película, que ya nos muestra imágenes en color, lo cual supone un gran avance en especial en obras cinematográficas dedicadas al ámbito artístico, es minuciosa y está muy bien documentada. En ella aparecen más de cien obras de Picasso que fueron distribuidas en seis partes: Saltimbanquis; vida y muerte de la pintura (1906-1934); El sueño de la razón (1937-1945); Faunos (Vallauris y Antibes); La colombe (Vallauris) y Picasso, la guerra y la paz.

- Expansión de la Relación entre Picasso y el cine.

La magnitud con la que se han expandido y proliferado las producciones audiovisuales que están relacionadas con Picasso a partir de los años sesenta, bien podrían ocupar la totalidad de un trabajo como el que aquí se presenta, siendo imposible su análisis completo a lo largo de

22 EMER, Luciano, op. cit. 


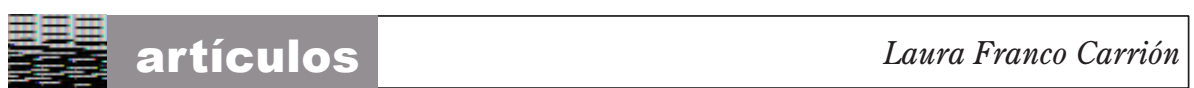

uno o dos capítulos únicamente.

Es cierto, como recogen las fuentes consultadas y ya citadas, que Picasso ya no es tratado por esas producciones audiovisuales a las que aludimos a partir de los sesenta, como pintor, sino como celebridad, a la altura de personalidades cercanas a ámbitos tan dispares como el de los deportes o el del toreo, por citar varios ejemplos.

Este hecho, unido al avance de la tecnología audiovisual, ha provocado y seguirá provocando un avance inabarcable de la relación entre el pintor y el medio de la imagen y el sonido, aunque en lo que respecta a la figura de Picasso como "creador audiovisual"o al menos como participante activo de obras audiovisuales, los ejemplos más significativos, sean los que se recogen en estos dos capítulos.

Convendría destacar sin embargo dos obras posteriores que adquieren importancia por diversos motivos como Le regard Picasso ${ }^{23}$ de Nelly Kaplan que incluye una amplísima revisión de la obra del pintor como motivo de la retrospectiva de 1966 en el Grand Palais de París o Picasso, The Sculptor, que realizó Roland Penrose en 1968 con un carácter más restringido a partir de la exposición del mismo nombre celebrada en la Tate Gallery de Londres.

Tanto el nonagésimo cumpleaños del artista en 1971 como su posterior muerte en 1973, dieron lugar a la proliferación de multitud de documentales y programas de televisión que se constituirían en forma de homenajes o balances de su trayectoria no solo profesional sino personal, a modo de reflexión o repaso por su vida y su papel en la historia del arte, distando de los enfoques que habían caracterizado estas películas en la década de los cincuenta.

Para finalizar este artículo, me gustaría trasladar de nuevo un fragmento de Sánchez Vidal entorno a la relación entre Picasso y el cine y que condensa algunas de las ideas esenciales entre la relación del artista con el medio audiovisual :

"La rapidez de reflejos que siempre le caracterizó le permite apercibirse de que ciertos componentes de su personalidad quedaban potenciados por la cámara. Así sucede con su gusto por el juego y la prestidigitación, su rapidez y seguridad de trazo, su virtuosismo, su interés por el proceso creador, al que podía asistir, así como un espectador privilegiado, su tendencia a la serialidad más que a la obra única y al desarrollo de una idea en varias direcciones posibles.

En esa tesitura, la cámara era un cómplice que le hacía justicia y lo convertía en una auténtica vedette"24.

23 1967. LE REGARD PICASSO.

Director : Nelly Kaplan.

Color, 52 minutos.

24 SÁNCHEZ VIDAL, Agustín, op. cit; p. 336 